\title{
Erratum
}

\section{Improvement of thrombocytopenia following bone marrow transplantation by pegylated recombinant human megakaryocyte growth and development factor in mice}

K Kabaya, K Shibuya, Y Torii, Y Nitta, M Ida, H Akahori, T Kato, M Kusaka and H Miyazaki

Bone Marrow Transplantation 1996; 18: 1035-1041

In Figures 3 and 4 of the above paper some additional asterisks appeared in the final published copy of the paper. Corrected versions of the figures follow.

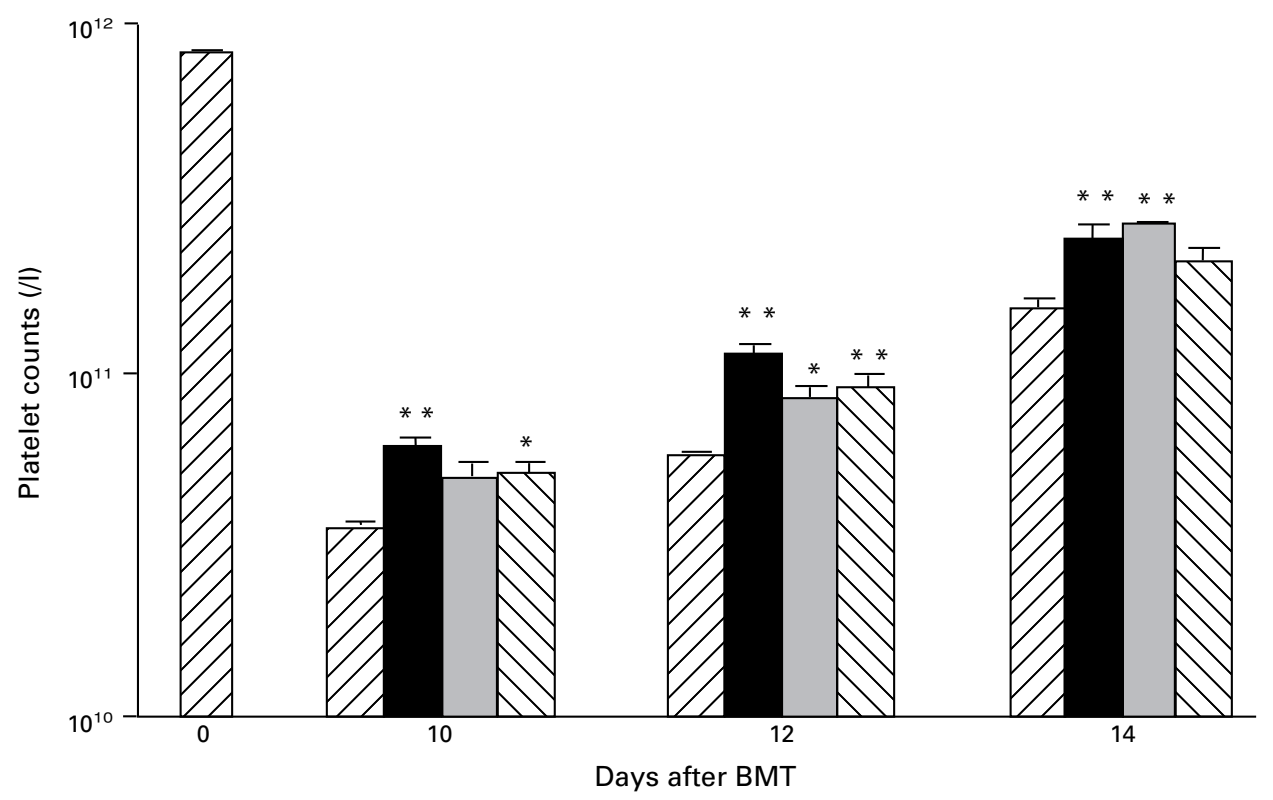

Figure 3 Administration schedules of PEG-rHuMGDF following BMT in mice. Subcutaneous administration schedules of PEG-rHuMGDF were shown as follows: (1) consecutive treatment at a dose of $30 \mu \mathrm{g} / \mathrm{kg} /$ day from the day after BMT (day 1) for 13 consecutive days ( $\square$ ); (2) alternate-day treatment

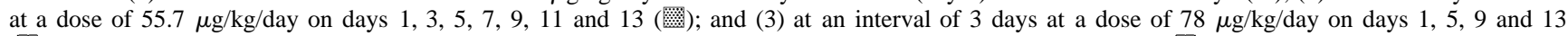
$(\mathbb{\nabla})$. The same volume of vehicle solution was injected as control from the day after BMT for 13 consecutive days ( $\bigotimes$ ). Each bar indicates the mean \pm s.e. of five to six mice. Significant differences $(* P<0.05$, $* * P<0.01)$ compared with the vehicle-treated mice were tested by Dunnett's test. 


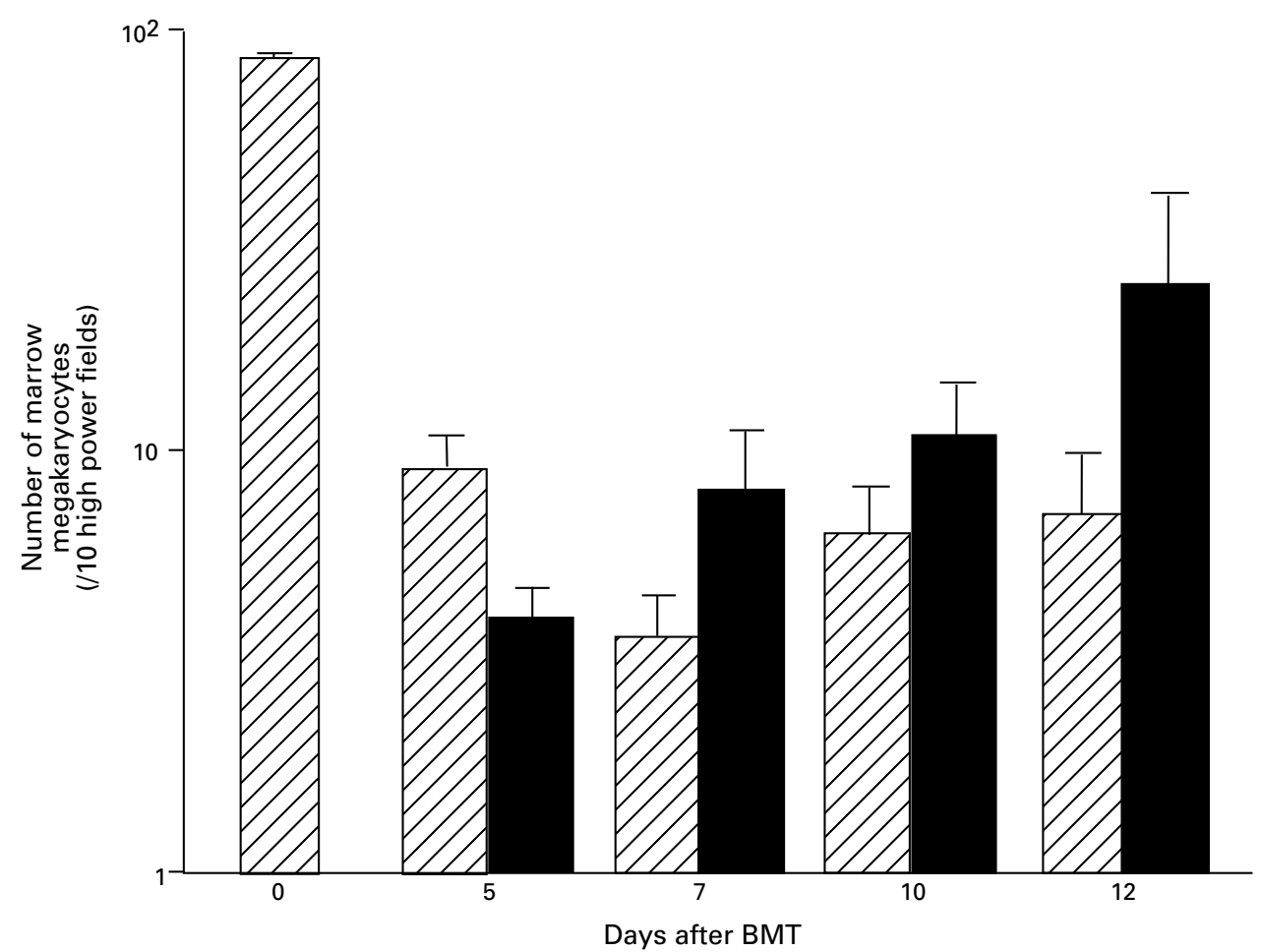

Figure 4 Effects of PEG-rHuMGDF on the number of marrow megakaryocytes following BMT in mice. PEG-rHuMGDF at a dose of $30 \mu \mathrm{g} / \mathrm{kg} / \mathrm{day}$ (ם) or vehicle solution ( 2 ) was administered subcutaneously from the day after BMT for 13 consecutive days. Each bar indicates the mean \pm s.e. of three to five mice. 